Ссылка: Бурденко E.В. Взаимосвязь рынка труда и рынка образовательных услуг. - М.: Издательство «Экономическое обозрение». Дизайн и технологии. № 1 (43). 2003. с. 238-244.

http://elibrary.ru/item.asp?id=24938102

\title{
ВЗАИМОСВЯЗЬ РЫНКА ТРУДА И РЫНКА ОБРАЗОВАТЕЛЬНЫХ УСЛУГ
}

Бурденко Елена Викторовна - почетный работник высшего профессионального образования, кандидат экономических наук, доцент кафедры политической экономии Российского экономического университета им. Г.В. Плеханова,

ResearcherID: E-3369-2014

orcid.org/0000-0001-5073-5062

burdenko-ev@yandex.ru

Аннотация

Статья посвящена проблемам взаимного приспособления рынка образовательных услуг и рынка труда. Рассмотрено взаимодействие между высшим образованием и рынком труда.

Ключевые слова: рынок образовательных услуг, рынок труда, рыночная экономика, высшее образование.

\section{THE RELATIONSHIP BETWEEN LABOR MARKET AND MARKET OF EDUCATIONAL SERVICES}

Burdenko, Elena V. - honorary worker of higher professional education, $\mathrm{PhD}$, Assistant Professor of the Department for Political Economy of the Plekhanov Russian University of Economics,

ResearcherID: E-3369-2014

orcid.org/0000-0001-5073-5062

burdenko-ev@yandex.ru

\begin{abstract}
The article is devoted to the problems of mutual adaptation of the educational services market and labour market. Interaction between higher education and the labour market.
\end{abstract}

Keywords: the educational services market, labor market, market economy, higher education. 
УДК: 331.37

ББК: Б-91

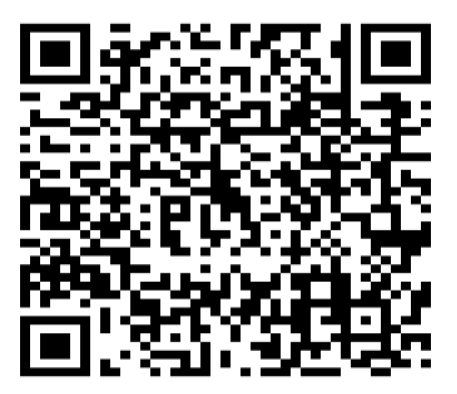

\author{
ВЗАИМОСВЯЗЬ РЫНКА ТРУДА И \\ РЫНКА ОБРАЗОВАТЕЛЬНЫХ УСЛУГ
}

\title{
Бурденко Е.B.
}

Рынок образовательных услуг, особенно среднесрочных и долгосрочных, тесно связан с рынком труда.

Взаимное приспособление рынка образовательных услуг и рынка труда зависит от формы обучения. Чем длиннее процесс предоставления и сроков образовательных услуг, тем больше временной лаг между взаимным приспособлением рынков, тем выше уровень неформальной неопределенности при выборе вида образовательных услуг, тем больше вероятность структурных диспропорций в профессиональной подготовке кадров.

Модель взаимного приспособления рынка образовательных услуг и рынка труда в экономической науке предложил Р.В. Фридмен. В его исследовании объем предложения квалифицированного труда - L является функцией не только ставки заработной платы - W, но и объема ежегодной подготовки квалифицированных рабочих - M, т.е. $\mathrm{L}=\mathrm{L}(\mathrm{WM})$. 
Объем спроса на образовательные услуги - М является функцией не только платы за обучение - h, но и ставки заработной платы квалифицированных рабочих, т.е. $\mathrm{M}=\mathrm{M}(\mathrm{hW})$.

Графически взаимное приспособление рынка образовательных услуг и рынка труда он изобразил в следующих схемах, представленных на рис. 1 $(\mathrm{a}$, б).

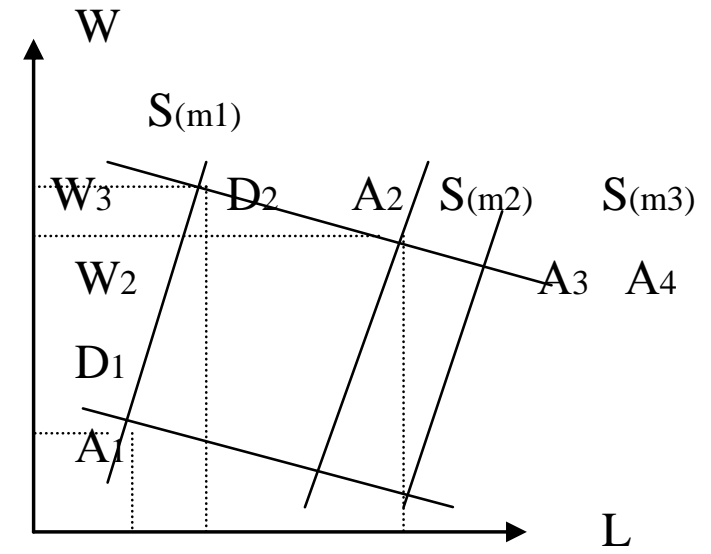

$\mathrm{L}_{1} \quad \mathrm{~L}_{2} \quad \mathrm{~L}_{3}$

a)

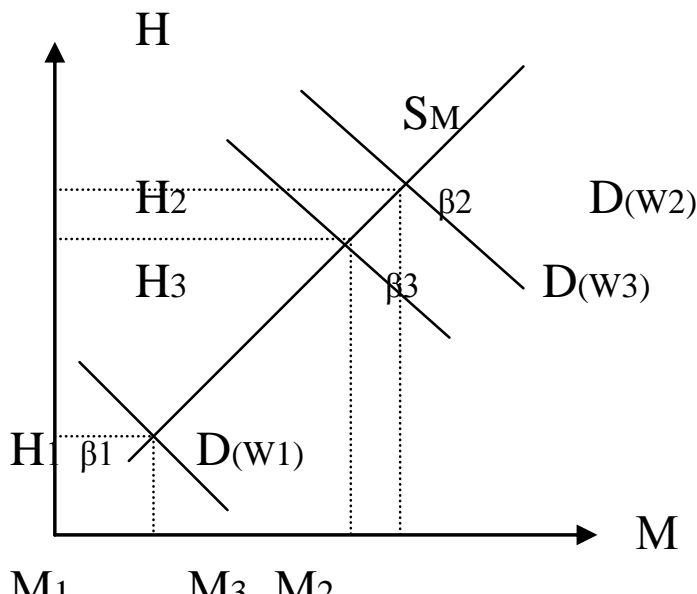

б)

Рис. 1. Взаимное приспособление рынка труда (а) и рынка образовательных услуг (б).

Система доказательства у Р.В. Фридмена строится на допущении, что первоначально (при кривой спроса на квалифицированную рабочую силу D1) рынок труда и рынок образовательных услуг находятся в равновесии при ставке заработной платы W1 и объеме занятости - L1 на рынке труда, плате за обучение - Н1 и численности обучаемых - M1 на рынке образовательных услуг. Пусть в следующий период спрос на квалифицированную рабочую силу возрос и характеризуется кривой - D2 (рис. 1). 
Каким образом определяются новые равновесные значения ставки заработной платы, платы за обучение, объема занятости и подготовки квалифицированной рабочей силы, если кривая предложения образовательных услуг $\mathbf{S}$ о осталась прежней?

В коротком периоде (при численности подготовки М1) ставки заработной платы поднимается до $\mathbf{W} 2$. При такой ставке заработной платы спрос на образовательные услуги будет характеризоваться кривой спроса Dм (W2) на рис. 1. В свою очередь, при таком спросе равновесие на рынке образовательных услуг возможно только при величине платы за обучение $\mathbf{H}_{2}$ и численности обучающихся $\mathbf{M 2}_{2}$ Но числу обучаемых М2 соответствует другая краткосрочная на рынке труда - S1(M2).

Следовательно, равновесие на одном графике не сочетается с равновесием на другом при рассмотренных значениях ключевых переменных. Однако взаимное приспособление переменных в конце концов приведет к такому набору их величин, при которых оба рынка будут пребывать в равновесии одновременно. Такая ситуация изображена точками Аз и В3. Равновесие на рынке труда Аз достигнуто при кривой предложения труда, соответствующей равноценному объему подготовки на рынке образовательных услуг Мз и этот последний определен с учетом той кривой спроса на образовательные услуги, которая соответствует равновесной ставке заработной платы, сложившейся на рынке труда.

Поэтому принципиальная возможность взаимного приспособления рынков базируется на совпадении интересов потребителей образовательных услуг и работодателей, что требует владение информацией о перспективах развития, имеющихся рабочих местах и т.д. Формирование такой информации возможно лишь при проведении мониторинга рынка образовательных услуг.

При исследовании спроса на товары и услуги в экономической теории различают ценовые (изменения величины спроса в зависимости от цен, 
движение по кривой спроса) и неценовые (изменения в самом спросе, перемещение самой кривой спроса) факторы. Соотношения этих факторов применительно и к образовательным услугам определяет платность и бесплатность этих услуг для индивидуального потребления. Во всех случаях потребитель руководствуется в выборе содержания и качества образовательной услуги теми возможными для него выгодами, которые могут быть получены при реализации полученного образования и профессиональной подготовки на рынке труда или во время какой-то другой деятельности. Размеры такой выгоды индивидуальный потребитель сопоставляет с издержками, которые ему предстоит понести для получения той или иной образовательной услуги.

При этом потребность в образовательной услуге как общественном благе выражается через механизм выбора, в виде принимаемых решений о поступлении в то или иное учебное заведение. Такие решения сильно зависят от мнения родителей, знакомых и т.д. Реализация потребности может сдерживаться правилами приема, имеющимся к моменту поступления, а также деформироваться соответствующей политикой государства. При индивидуальном потреблении возникают следующие издержки: во-первых, деньги, которые необходимо уплатить за обучение, если оно платное; во-вторых, труд, который потребуется затратить обучающемуся на приобретение знаний, навыков и умении (например, трудность учебного материала на физико-математических факультетах по сравнению с гуманитарными факультетами); в-третьих, особый вид образуют вмененные издержки, значение которых возрастает по мере проникновения рыночных механизмов в сферу образования.

Суть вмененных издержек заключается в том, что, затрачивая время и энергию на приобретение образования, индивидуальный потребитель тем самым жертвует другими, альтернативными возможностями использования своего времени и применения своей энергии. Величина 
вмененных издержек определяется размерами выгоды или других видов полезности, которые могут быть получены при альтернативных способах использования индивидуальным потребителем своих личных ресурсов (например, если выпускник средней школы может найти способы зарабатывания достаточно крупных денежных сумм без обучения в вузе, то вмененные издержки вузовского обучения для этого индивидуума окажутся достаточно большими).

Но реальная ситуация в России сейчас демонстрирует нечто противоположное. Возможности трудоустройства приемлемые для выпускников средних общеобразовательных школ, на современном рынке труда весьма ограничены. Кроме того, для юношей существует альтернатива - мало привлекательная для большинства из них военная служба, от обязанности которой освобождаются студенты высших учебных заведений. В таких условиях выбор в пользу высшего образования происходит при минимальных или даже отрицательных вмененных издержках. Именно этими обстоятельствами вызван заметный рост в последние годы числа абитуриентов. Связь между высшим образованием и рынком труда показана на рис. 2.

\begin{tabular}{|c|c|c|}
\hline $\begin{array}{c}\text { ВЫСШЕЕ } \\
\text { ОБРАЗОВАНИЕ }\end{array}$ & & РЫНОК ТРУДА \\
\hline 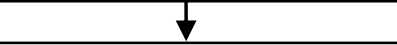 & $\downarrow$ & 7 \\
\hline $\begin{array}{l}\text { Обеспечивает: } \\
\text { обучение } \\
\text { (количество } \\
\text { выпускников, знания } \\
\text { и умения) } \\
\text { Научные } \\
\text { исследования и } \\
\text { формирование } \\
\text { знаний }\end{array}$ & $\begin{array}{l}\text { Как регулируется? } \\
\text { Кто регулирует? } \\
\text { Правительство } \\
\text { Работодатели } \\
\text { Высшее } \\
\text { образование } \\
\text { студенты }\end{array}$ & $\begin{array}{l}\text { Характеристики: } \\
\text { Знания и основы } \\
\text { умений } \\
\text { Рост и изменения } \\
\text { Сегментация } \\
\text { Профессиональные } \\
\text { ценности }\end{array}$ \\
\hline $\begin{array}{l}\text { Механизмы: } \\
\text { Учебный план } \\
\text { (влияние внешних } \\
\text { факторов на } \\
\text { внутренние, } \\
\text { например: рынка } \\
\text { труда на } \\
\text { ориентацию }\end{array}$ & $\begin{array}{l}\text { Также отражает: } \\
\text { Переоценка } \\
\text { ценности работ } \\
\text { Изменения знаний, } \\
\text { структуры ценностей }\end{array}$ & $\begin{array}{l}\text { Требования: } \\
\text { Подготовленный и } \\
\text { образованный } \\
\text { персонал } \\
\text { Модернизация и } \\
\text { переподготовка } \\
\text { Предварительный } \\
\text { отбор и отсев }\end{array}$ \\
\hline
\end{tabular}


Рис. 2. Связь между высшим образованием и рынком труда.

Главная особенность рыночного спроса на образовательные услуги, ограничивающая его регулирующее значение для развития сферы образования - это его принципиальная неспособность транслировать образовательной системе перспективные потребности в масштабах и структуре образовательных услуг. Здесь требуется разработка научно обоснованного прогноза развития на среднесрочный и долгосрочный периоды.

Следовательно, на рынке образовательных услуг необходимо дополнять рыночный механизм инструментарием государственного регулирования. Это следует иметь в виду при характеристике спроса и предложения образовательных услуг. Высшие и средние учебные заведения предлагают потребителям общеобразовательное и профессиональное образование разных уровней и специальностей, предоставляя свободу выбора людям, желающим получить те или иные образовательные услуги. Как и на всяком рынке, развертывается конкуренция образовательных учреждений за привлечение учащихся. С усилением конкуренции возникает необходимость в маркетинговых подходах.

Анализ рынков труда и образовательных услуг, предлагаемый в литературе, позволяет представить следующую схему (рис. 3).

Представленная схема иллюстрирует взаимосвязь рынка труда и рынка образовательных услуг. Интересы работодателей и их требования к труду (правая часть схемы) более или менее точно отражает процесс 
определения количества людей, которых необходимо подготовить к той или иной профессии на любом образовательном уровне. Этот процесс базируется на концепции, названной «резерв талантов», которая в последнее время приобрела особое значение.

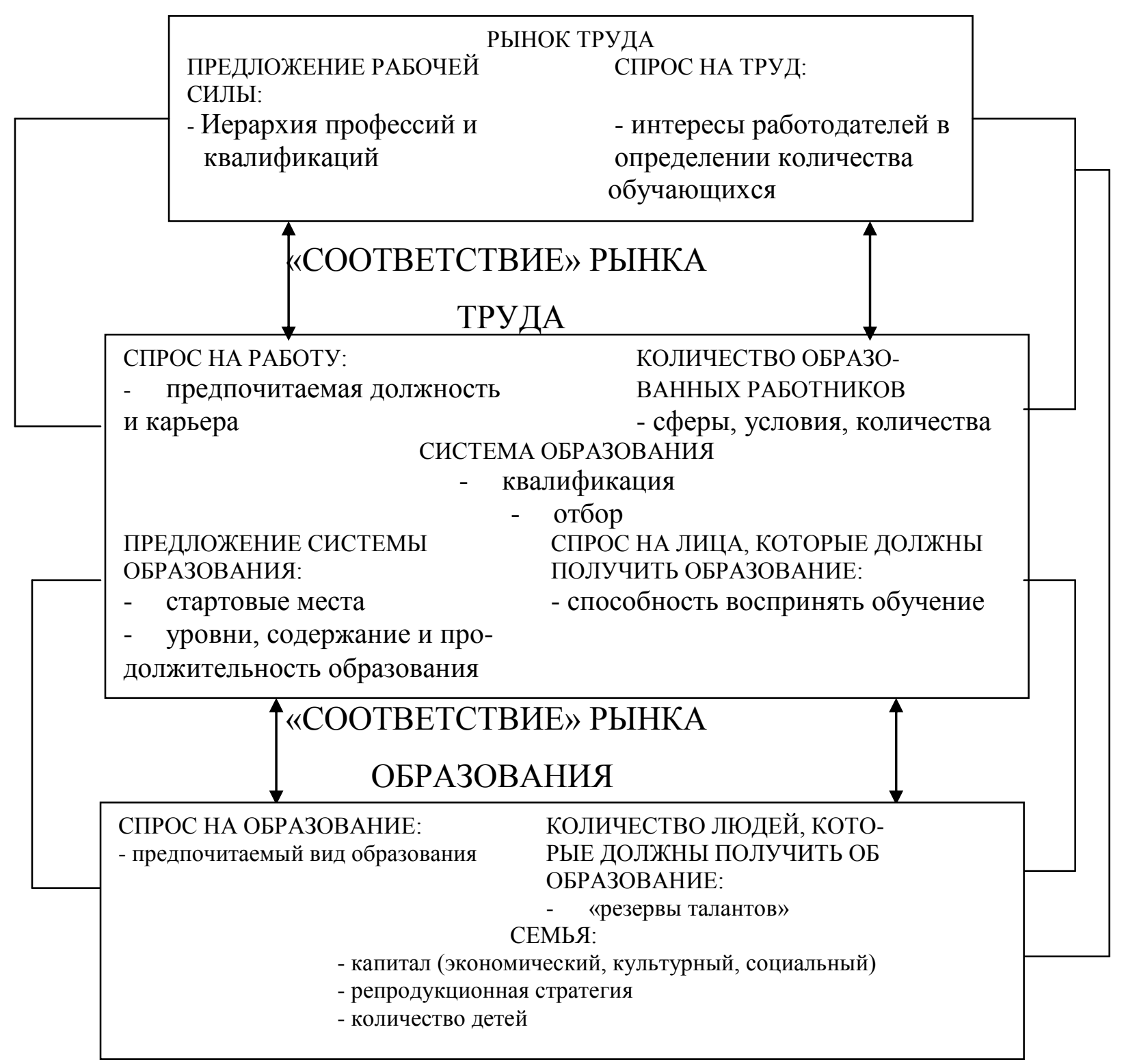

Рис. 3. Рынки труда и образовательных услуг. 
Левая часть схемы отражает спрос на образование, который проявляется в виде предпочтения тому или иному типу образования, а также предложение системы образования, выраженное количеством стартовых мест. На рынке образования, выбор вида обучения во многом определяется различными формами капитала семьи (экономического, культурного, социального) и ее репродукционной стратегией. Равновесие спроса и предложения устанавливается рынком труда. Склонность к той или иной деятельности формируется частично во время обучения, а частично - под влиянием таких факторов как семья, мода и т.д. Из-за несовпадения образовательных склонностей семей и интересов работодателей, возникает дисбаланс на рынке образовательных услуг и рынке труда. Число стремящихся получить образование не соответствует числу мест в системе образования, также как и число будущих работников не соответствует числу рабочих мест.

В современных условиях взаимодействия рынка труда и рынка образовательных услуг значимость формальной квалификации несколько уменьшается, но возрастает роль элитного образования, получаемого в престижных или частных учебных заведениях.

Особый рыночный сектор заполняется образовательными услугами частных учебных заведений и платным обучением в престижных государственных вузах. Они занимают эту нишу, реагируя своим предложением на разновидность спроса. Наличие спроса на платные образовательные услуги определяется целым рядом факторов: во-первых, в процессе перехода к рыночной экономике формируется сравнительно немногочисленный слой богатых людей, которые в состоянии высоко оплачивать образовательные услуги, инвестировать капитал в своих детей, их личное будущее; во-вторых, более массовый спрос на образовательные услуги элитных частных учреждений, обусловлен стремлением родителей обеспечить своим детям более высокий уровень образования по сравнению 
с обычными нормами и стандартами в знании иностранных языков, экономических дисциплин, информатики и в других областях современных моделей образованности.

Все вышеприведенное позволяет сделать вывод о том, что в современном обществе усложняется взаимодействие системы образования и рынка труда. При этом особенностью рынка образовательных услуг является его неоднородность. Последняя обусловлена множеством сегментных, взаимосвязанных рынков, которые формируются под влиянием различных обстоятельств: уровня и ступени образования, типа учебного заведения, уровня подготовки, пола, возраста, семейного положения и других факторов.

Формирование и функционирование рынка образовательных услуг подчиняется, конечно, общим законам рыночной экономики, однако обладает рядом специфических особенностей. Из них выделяются следующие: высокий динамизм; территориальная сегментация и локальный характер; значительная скорость оборота капитала; большая чувствительность образовательных услуг к рыночной конъюнктуре в силу невозможности их складирования и транспортирования; индивидуальность производства и т.д. Рыночные отношения производства образовательных услуг имеют специфику, связанную с государственным вмешательством и регулированием наиболее значимых услуг, а также с ограничениями на частнопредпринимательскую деятельность.

Список используемых источников:

1. Закон Российской Федерации «Об образовании» (в редакции, введенной в действие с 1996г. № 12-Ф3) // Собрание законодательства Российской Федерации.-1996.-№3 - с.693-735.

2. Зиннуров У.Г. «Маркетинг в деятельности вузов»// Москва - Уфа, 1993 г. 
3. Иванов Ю.И., Русинов Ф.М. Рынок, предпринимательство, кадры/ под науч. ред. Г.В. Горланова, С.Е. Хорзова. - М.: РАУ. 1992.

4. Бурденко Е.В., Алиматов Д.Г. Образование и развитие человеческого капитала - главные факторы экономического развития // Межвузовский сборник научных трудов, вып.№3. - М.: Изд. МГУДТ, 2002.- 0,5 п.л.

5. Бурденко Е.В. Институциональные основы государственной политики на рынке образовательных услуг. М.: Изд. МГУДТ, 2002. - 0,8 п.л. 